\title{
Intense immunosuppression in chronic progressive multiple sclerosis: the Kaiser study
}

\author{
William H Likosky, Bruce Fireman, Robert Elmore, Gary Eno, Kirby Gale, \\ G Browne Goode, Katherine Ikeda, James Laster, Carter Mosher, Jack Rozance, \\ Joel Richmon, Sidney Rosenberg, Antoine Samman, Robert Sternbach, Jay Whaley, \\ Louis Fehrenbacher
}

Kaiser Permanente Medical Center, California, USA Departments of Neurology Santa Clara

W H Likosky

R Elmore

J Laster

Vallejo

G Eno

K Gale

A Samman

San Francisco

G B Goode

South San Francisco S Rosenberg

Martinez

K Ikeda

Sacramento

C Mosher

J Rozance

Oakland

J Richmon

Walnut Creek

R Sternbach

Redwood City

J Whaley

Department of

Medicine

Vallejo

L Fehrenbacher

Kaiser Permanente Medical Care

Program, Oakland,

California

Division of Research

B Fireman

Correspondence to

Dr Likosky, Department of Neurology, Kaiser

Permanente Medical Center, 900 Kiely Blvd, Santa Clara, CA 95051, USA

Received 3 September 1990 and in revised form 5 April 1991

Accepted 16 April 1991

\begin{abstract}
The value of a short course of intensive immunosuppression with cyclophosphamide in stabilising chronic progressive multiple sclerosis (MS) was examined in a randomised singleblinded, placebo-controlled clinical trial. Forty two patients, from the Kaiser Permanente Medical Care Program, Northern California, were studied. Twenty two patients received a short course of cyclophosphamide in an outpatient neurology clinic until their leucocyte counts fell below $4000 / \mathrm{mm}^{3}$, and 20 patients received folic acid. Level of disability, impairment of functional systems, and performance of social roles were assessed before randomisation and reassessed 12, 18, and 24 months after therapy. In both the cyclophosphamide and folic acid groups, the mean level of disability increased from the baseline examination to the 12 month follow up examination (the primary endpoint) by 0.5 on Kurtzke's Expanded Disability Status Scale, indicating similar disease progression in the two groups. Although immunosuppression therapy can be safely administered to MS patients in an outpatient clinic, evidence of substantial benefits was not found.
\end{abstract}

Multiple sclerosis (MS) is a common cause of neurological disability. The majority of patients experience a relatively benign course with exacerbations and remissions. In a proportion of patients, however, the disease may enter a chronic progressive phase and proceed to severe disability. ${ }^{1}$ We examined whether immunosuppression can stabilise this chronic progressive form of the disease.

The disease process of MS consists of the breakdown of myelin in the central nervous system accompanied by inflammation and eventual scarring. ${ }^{2}$ A body of evidence implicates a disordered immune system in the pathogenesis of $\mathrm{MS}^{34}$ As a result, a number of immune-system-altering agents have been used to treat the acute and chronic progressive forms of the disease. ${ }^{5}$

No specific therapy has been shown to alter the long-term prognosis for patients with the disease ${ }^{67}$ Following Aimard et $a l^{8}$ and Girard et $a l,{ }^{y}$ some work has suggested that the immunosuppressant cyclophosphamide (CTX) alone or in conjunction with adrenocorticotropic hormone (ACTH) or prednisone may favourably modify the progression of MS. ${ }^{10-18}$ Treatment with CTX has potential short- and long-term potential toxicities mandating more complete evaluation of efficacy before routine use in chronic progressive MS. ${ }^{19-21}$

This study was designed to test the utility of a short course of intensive immunosuppression with CTX compared with a placebo of folic acid (FA) in stabilising chronic progressive MS. We also tested whether such immunosuppression could be safely administered in outpatient neurology clinics. The physicians evaluating disease were blind to patients' treatment status.

\section{Methods}

The study was conducted at outpatient neurology clinics of the Kaiser Permanente Medical Care Program in Northern California. This health maintenance organisation provides medical care for about two million health plan members at 14 medical centres. Patients were referred to the study by 19 neurologists at 13 of the centres. Seven neurologists and one oncologist treated patients; seven neurologists evaluated patients.

Patients who met the following criteria were eligible for the study: 1) History, physical examination, and laboratory findings consistent with MS and meeting the Schumacher criteria for the diagnosis of $M S ;^{22}$ 2) Chronic progressive disease for one or more years as established by clinical records and patient and physician assessments. Chronic progressive disease was defined as an estimated drop in the Kurtzke Expanded Disability Status Scale $(\mathrm{EDSS})^{23}$ and the Ambulation Index (AI $)^{10}$ by one step over the previous year and a gradual pattern of disease progression with or without superimposed acute exacerbations; 3) Gait impairment but ability to walk retained; 4) Age at entry into study between 18 and 60 years; 5) Absence of debilitating chronic disease or recent immunosuppressive therapy. Informed consent was obtained from all participating patients.

Cyclophosphamide (400 to $500 \mathrm{mg}$ ) was 
Table 1 Baseline characteristics of 22 patients treated with cyclophosphamide and 20 patients treated with folic acid

\begin{tabular}{|c|c|c|c|c|}
\hline & \multicolumn{2}{|c|}{ CTX group } & \multicolumn{2}{|c|}{ FA group } \\
\hline & Mean & (range) & Mean & (range) \\
\hline $\begin{array}{l}\text { Age, year } \\
\text { Per cent women } \\
\text { Number years since onset of symptoms } \\
\text { Age of onset of illness, year } \\
\text { Expanded disability status scale (EDSS) } \\
\text { Ambulation index (AI) }\end{array}$ & $\begin{array}{c}43 \cdot 9 \\
54 \cdot 6 \\
9 \cdot 2 \\
34 \cdot 6 \\
5 \cdot 84 \\
4 \cdot 3\end{array}$ & $\begin{array}{l}(31-58) \\
(1-16) \\
(22-52) \\
(3-8) \\
(2-9)\end{array}$ & $\begin{array}{r}40 \cdot 8 \\
40 \cdot 0 \\
11 \cdot 5 \\
29 \cdot 3 \\
5 \cdot 8 \\
4 \cdot 3\end{array}$ & $\begin{array}{l}(25-55) \\
(1-29) \\
(19-42) \\
(2-7) \\
(2-7)\end{array}$ \\
\hline
\end{tabular}

CTX = cyclophosphamide.

$\mathrm{FA}=$ folic acid positive change scores indicated more severe impairment.

Disease progression among patients in the two groups was also examined using dichotomous indicators obtained from the EDSS, the AI, each component of the FSS, the IS, and the ES. We categorised patients as "worse" if their follow up rating was at a level of disability at least 1.0 units higher than their baseline rating; otherwise they were categorised as "stable."

Evaluating physicians were unaware of the treatment status of the patients they evaluated. Hair loss among CTX patients was brief and did not bias evaluation; their hair had regrown by the time the one year examination took place. The senior author, blind to patient treatment status, reviewed the ratings of the nine evaluating physicians to ensure that they consistently followed the criteria specified in the protocol.

\section{Statistical methods}

The "benefit" of CTX treatment at each follow up examination was estimated by the amount that the mean EDSS change in the CTX group exceeded that in the FA group. The null hypothesis-that EDSS change in the CTX group does not exceed that in the FA groupwas evaluated using a two sided $t$ test. Multiple regression models were fitted to the data to adjust comparisons of group means for differences between the groups (despite randomisation) in baseline EDSS, age, sex, and duration of disease. The nonparametric Wilcoxon test was also used to compare the distribution of EDSS change scores in the CTX group with that in the FA group. Also, the logrank test was used to compare the two groups with respect to time until "failure," defined as a worsening of at least one step on the EDSS, was sustained at the subsequent examination and not later reversed. Finally, the chisquared test was used to evaluate the difference between the groups at each follow up examination in the proportion of patients whose EDSS change was $<1$ level (indicating that their condition was stable).

Similar methods were used to assess other indicators of treatment benefit, including change in the AI, the FSS, the ES, and the IS.

The primary endpoint was the EDSS change at one year. We report nominal $p$ values associated with a number of additional hypothesis tests, recognising that even if CTX treatment has no benefits, we might find a few $p$ values slightly below 0.05 .

\section{Randomisation and treatment}

Forty three patients met the eligibility criteria between April 1983 and March 1986 and entered the study. Twenty two were randomised to the CTX group and 21 to the FA group. One in the FA group was subsequently dropped from the study when it was determined that the patient had motor neuron disease rather than MS. Another FA patient insisted on immune suppression therapy shortly after receiving $F A$ and received a course of CTX. A third FA patient received CTX as 
Table $3 a$ Patients treated with cyclophosphamide (CTX): baseline characteristics, leucopenia, and EDSS at 12,18, and 24 months

\begin{tabular}{|c|c|c|c|c|c|c|c|c|c|c|}
\hline \multirow{2}{*}{$\begin{array}{l}\text { Patient } \\
\text { number }\end{array}$} & \multirow[b]{2}{*}{ Sex } & \multirow{2}{*}{$\begin{array}{l}\text { Age at } \\
\text { baseline } \\
\text { (year) }\end{array}$} & \multirow{2}{*}{$\begin{array}{l}\text { Age at } \\
\text { onset } \\
\text { of } M S \\
\text { (year) }\end{array}$} & \multicolumn{2}{|l|}{$C T X$} & \multirow{2}{*}{$\begin{array}{l}\text { Lowest } \\
\text { lymphocyte } \\
\text { count } \\
\left(\mid \mathrm{mm}^{3}\right)\end{array}$} & \multicolumn{2}{|l|}{$E D S S$} & \multicolumn{2}{|l|}{$E D S S$} \\
\hline & & & & $(m g)$ & $(m g / k g)$ & & Baseline & 12 months & 18 months & 24 months \\
\hline 1 & F & 43 & 34 & 4000 & 51 & 510 & 6.0 & 3.5 & 3.5 & $4 \cdot 0$ \\
\hline $4^{\star}$ & $\mathbf{F}$ & 49 & 39 & 3200 & 65 & 225 & 8.0 & 9.5 & 10.0 & 10.0 \\
\hline 6 & $\mathbf{F}$ & 45 & 37 & 5000 & 86 & 240 & 6.0 & 5.5 & 3.5 & 4.0 \\
\hline $8 \dagger$ & $\mathbf{M}$ & 41 & 33 & 14800 & 201 & 273 & 6.5 & 8.0 & $9 \cdot 0$ & ND \\
\hline 10 & $\mathbf{F}$ & 37 & 32 & 2800 & 54 & 496 & $4 \cdot 5$ & 4.5 & 4.5 & 5.5 \\
\hline 12 & $\mathbf{F}$ & 40 & 32 & 3500 & 65 & 462 & $6 \cdot 0$ & $6 \cdot 0$ & $6 \cdot 0$ & 6.0 \\
\hline 13 & $\mathbf{F}$ & 47 & 33 & 4000 & 52 & 420 & $6 \cdot 5$ & 6.5 & 6.5 & 6.5 \\
\hline 16 & $\mathbf{M}$ & 46 & 44 & 7000 & 94 & 493 & $6 \cdot 0$ & 6.0 & 6.5 & 6.5 \\
\hline $18 \ddagger$ & $\mathbf{M}$ & 58 & 52 & 5500 & 82 & 272 & 6.5 & $7 \cdot 0$ & ND & ND \\
\hline 20 & $\mathbf{M}$ & 50 & 46 & 5000 & 82 & 180 & $6 \cdot 0$ & 8.0 & 8.0 & 8.0 \\
\hline 22 & $\mathbf{M}$ & 34 & 32 & 5000 & 65 & 456 & 6.0 & $7 \cdot 0$ & $7 \cdot 0$ & 7.0 \\
\hline 23 & $\mathbf{M}$ & 31 & 30 & 8000 & 107 & 513 & 3.0 & 3.0 & 3.0 & 5.5 \\
\hline 25 & $\mathrm{~F}$ & 57 & 44 & 2500 & 44 & 350 & 6.0 & 6.0 & 6.0 & 6.5 \\
\hline 26 & $\mathbf{M}$ & 38 & 22 & 7100 & 77 & 399 & 5.0 & $6 \cdot 5$ & 6.5 & 6.0 \\
\hline 28 & $\mathbf{F}$ & 38 & 24 & 4500 & 65 & 805 & 6.5 & 8.0 & 8.0 & 8.0 \\
\hline 31 & $\mathrm{~F}$ & 45 & 35 & 2500 & 33 & 124 & 6.0 & $6 \cdot 0$ & $6 \cdot 0$ & 3.5 \\
\hline 33 & $\mathbf{F}$ & 53 & 38 & 3000 & 38 & 323 & 6.0 & $7 \cdot 0$ & $7 \cdot 0$ & $7 \cdot 5$ \\
\hline 35 & $\mathbf{M}$ & 39 & 30 & 5000 & 54 & 456 & 3.5 & 6.0 & 3.5 & 6.0 \\
\hline 37 & $\mathrm{~F}$ & 51 & 35 & 3000 & 42 & 782 & 6.0 & 6.5 & 6.5 & 7.5 \\
\hline 39 & $M$ & 41 & 26 & 3000 & 34 & 560 & 6.5 & 6.5 & ND & 6.5 \\
\hline 40 & $\mathrm{~F}$ & 39 & 32 & 3000 & 49 & 80 & 6.0 & 6.5 & 6.0 & ND \\
\hline 42 & $\mathbf{M}$ & 43 & 32 & 5000 & 64 & 696 & 6.0 & 6.0 & 6.0 & 6.0 \\
\hline
\end{tabular}

*Died of MS 18 months after treatment.

+ Died of lung cancer 20 months after treatment.

$\ddagger$ Died of myocardial infarction 15 months after treatment.

ND $=$ No data.

cancer chemotherapy just before the 24 month follow up examination. Unless otherwise noted, results reported below omit the patient with motor neuron disease and include the two "crossovers" in the FA group.

At the baseline examination, before randomisation, the CTX patients were similar to the FA patients in demographic characteristics and extent of neurological impairment (table 1). Compared with the FA group, the CTX group had a mean age $3 \cdot 1$ years higher, included more women, averaged 2.3 years less since the onset of MS symptoms, and were $5 \cdot 3$ years older at onset of illness. Such differences are not surprising given the modest size of the groups. The distributions of baseline ratings on the EDSS and the AI are similar, suggesting that the groups are well matched.

The distributions of CTX dose and subsequent leucopenia among the $22 \mathrm{CTX}$ patients

Table $3 b$ Patients treated with folic acid $(F A)$ : baseline characteristics and EDSS at 12,18 , and 24 months

\begin{tabular}{|c|c|c|c|c|c|c|c|}
\hline \multirow{2}{*}{$\begin{array}{l}\text { Patient } \\
\text { number }\end{array}$} & \multirow[b]{2}{*}{ Sex } & \multirow{2}{*}{$\begin{array}{l}\text { Age at } \\
\text { baseline }\end{array}$} & \multirow{2}{*}{$\begin{array}{l}\text { Age at } \\
\text { onset }\end{array}$} & \multicolumn{2}{|l|}{ EDSS } & \multicolumn{2}{|l|}{$E D S S$} \\
\hline & & & & Baseline & 12 months & 18 months & 24 months \\
\hline $2^{\star}$ & $\mathbf{F}$ & 36 & 19 & 2.0 & 2.0 & 2.5 & 3.0 \\
\hline 3 & $\mathbf{M}$ & 45 & 23 & 6.0 & 7.0 & 8.0 & 6.5 \\
\hline $5 t$ & F & 25 & 21 & 5.5 & 7.5 & 8.0 & 8.0 \\
\hline 7 & $\mathbf{F}$ & 42 & 38 & 6.5 & 9.5 & 9.5 & 9.5 \\
\hline 9 & $\mathbf{F}$ & 42 & 33 & 6.5 & 6.5 & 6.5 & 6.5 \\
\hline 11 & $\mathrm{~F}$ & 29 & 24 & 5.0 & 7.5 & $7 \cdot 0$ & $7 \cdot 5$ \\
\hline 14 & M & 50 & 22 & 6.5 & 6.0 & 6.5 & 6.5 \\
\hline 15 & $\mathbf{M}$ & 55 & 37 & 6.5 & 6.0 & 5.0 & 6.0 \\
\hline 17 & $\mathbf{M}$ & 42 & 32 & $6 \cdot 0$ & $6 \cdot 0$ & 6.0 & 6.5 \\
\hline 19 & $\mathbf{M}$ & 31 & 27 & 3.0 & 2.0 & 2.0 & 3.0 \\
\hline 21 & $\mathbf{M}$ & 46 & 42 & 6.5 & 6.5 & 6.5 & 6.5 \\
\hline 24 & $\mathbf{M}$ & 46 & 41 & 7.0 & 7.5 & 8.0 & $8 \cdot 5$ \\
\hline 27 & $\mathrm{~F}$ & 41 & 34 & 6.5 & 8.0 & 8.5 & $8 \cdot 5$ \\
\hline 29 & $\mathbf{F}$ & 49 & 20 & 5.0 & 5.0 & $5 \cdot 0$ & 6.0 \\
\hline 30 & $\mathbf{F}$ & 28 & 18 & 6.5 & 7.5 & 7.5 & ND \\
\hline 32 & $\mathbf{M}$ & 46 & 41 & 5.5 & 5.5 & 6.0 & 6.0 \\
\hline 34 & $\mathbf{M}$ & 30 & 25 & 5.5 & $6 \cdot 0$ & 6.5 & $7 \cdot 0$ \\
\hline 36 & $\mathbf{M}$ & 54 & 40 & $6 \cdot 0$ & 6.5 & 6.5 & 6.5 \\
\hline 38 & $M$ & 31 & 30 & $7 \cdot 0$ & 7.0 & 7.5 & ND \\
\hline 41 & $\mathbf{M}$ & 48 & 19 & 6.5 & 6.5 & $7 \cdot 0$ & ND \\
\hline
\end{tabular}

*Received low-dose CTX chemotherapy for cancer at 17 months. tReceived CTX for MS at 3 months.

No $=$ No data are described in table 2. The mean dose of CTX was $69 \mathrm{mg} / \mathrm{kg}$; the range was $33-201 \mathrm{mg} / \mathrm{kg}$. The mean pretreatment leucocyte and lymphocyte counts were $7855 / \mathrm{mm}^{3}$ and $1677 / \mathrm{mm}^{3}$, respectively. During CTX treatment, the leucocyte and lymphocyte counts declined substantially in all 22 patients; the mean of the lowest leucocyte and lymphocyte counts were $2045 / \mathrm{mm}^{3}$ and $414 / \mathrm{mm}^{3}$, respectively. Eighteen CTX patients had a leucocyte count below $2500 / \mathrm{mm}^{3}$. The other four CTX patients had leucocyte counts of $2700 / \mathrm{mm}^{3}, 2900 / \mathrm{mm}^{3}$, $3100 / \mathrm{mm}^{3}$, and $3400 / \mathrm{mm}^{3}$.

After treatment, toxicity was recognised in all CTX-treated patients. All 22 temporarily lost their hair. Nine had nausea with vomiting; another seven had nausea without vomiting. In no case was nausea or vomiting severe, and in no case did it preclude continuation of therapy. Gross or microscopic haematuria was not encountered.

\section{Results}

Our primary measure of neurological impairment, the EDSS, is presented for each patient for each examination in tables 3a (CTX patients) and 3b (FA patients). At one year follow up, $14(64 \%)$ of 22 CTX patients appeared stable (that is, EDSS unchanged or improved), compared with $14(70 \%)$ of the 20 FA patients (fig). By 24 month follow up, nine $(47 \%)$ of 19 CTX patients appeared stable, compared with nine $(53 \%)$ of 17 FA patients. The small differences between the two groups could be a result of chance alone.

In each group, the mean EDSS change from the baseline examination to the one year follow up examination, the primary endpoint, was approximately 0.5 (table 4 ). The upper bound of the $95 \%$ confidence interval surrounding the estimate of treatment benefit suggests we can rule out a treatment benefit amounting to more than 0.65 steps on the EDSS. Similar results 
Figure Graphshows disease stabilisation by treatment group and time.

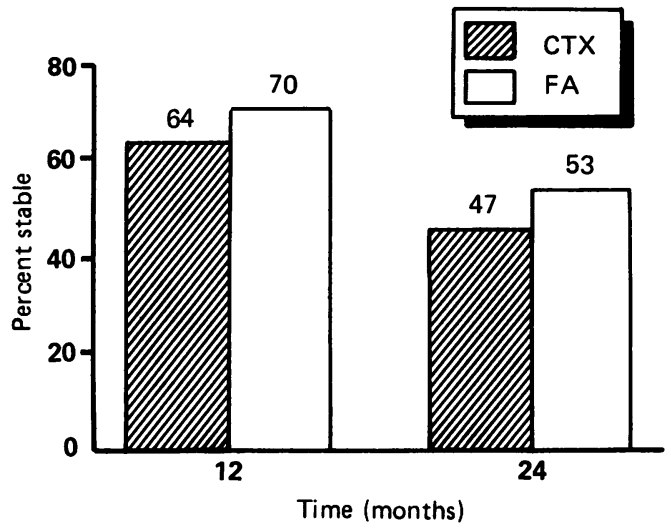

are obtained when the AI or the FSS are used to estimate treatment effects. During the first year, the level of impairment worsened slightly more in the CTX group than in the FA group: by 0.05 units on the AI and by 0.21 units on the FSS.

Unlike the first year, the second year EDSS change scores suggest somewhat more stability in the CTX group than in the FA group (table 4). However, the $95 \%$ confidence intervals at 18 and 24 months are wide; they suggest that our results for the second year do not permit us to rule out either a lack of treatment benefit or a sizeable treatment benefit. The AI and FSS also suggest more disease progression among FA patients than among CTX patients at 18 and 24 months, also with wide confidence intervals.

The group differences in mean EDSS change could be attributable to chance alone: associated p values were 0.94 at 12 months, 0.36 at 18 months, and 0.37 at 24 months. Evaluation of group differences in mean change on the AI and FSS at 12, 18, and 24 months indicated that group differences in these outcome measures could also be attributable to chance alone.

Change in EDSS from the baseline examination to the one year follow up examination was only slightly related to sex, age, duration of MS, and baseline EDSS level. Adjustment of our estimate of treatment benefit for these covariates using multiple regression did not appreciably alter its size or statistical significance: the adjusted difference in mean EDSS change was 0.01 . Similarly, adjustment for these covariates did not appreciably alter estimates of treatment benefits at 18 or 24 months.

Nonparametric tests also indicated that group differences in EDSS change scores could be attributable to chance alone. The $p$ values associated with Wilcoxon tests of group differences in EDSS change scores at 12, 18, and 24 months were $0.71,0.38$, and 0.70 ,

Table 4 Mean change in expanded disability status scale and ambulation index from baseline to follow up at 12,18, and 24 months by treatment group

\begin{tabular}{|c|c|c|c|c|c|c|}
\hline \multirow{2}{*}{$\begin{array}{l}\text { Follow up } \\
\text { interval }\end{array}$} & \multirow[b]{2}{*}{ Measure } & \multicolumn{2}{|c|}{ CTX } & \multicolumn{2}{|l|}{$F A$} & \multirow{2}{*}{$\begin{array}{l}\text { FA mean } \\
\text { minus } C T X \\
\text { mean }(95 \% \text { CI })\end{array}$} \\
\hline & & $n$ & mean & $n$ & mean & \\
\hline $0-12$ months & $\begin{array}{l}\text { EDSS } \\
\text { AI }\end{array}$ & 22 & $\begin{array}{l}0.50 \\
1.05\end{array}$ & 20 & $\begin{array}{l}0.53 \\
1.00\end{array}$ & $\begin{array}{r}0.03(-0.60,0.65) \\
-0.05(-0.98,0.89)\end{array}$ \\
\hline 0-18 months & $\begin{array}{l}\text { EDSS } \\
\text { AI }\end{array}$ & 20 & $\begin{array}{l}0.38 \\
1.10\end{array}$ & 20 & $\begin{array}{l}0.73 \\
1.75\end{array}$ & $\begin{array}{l}0.35(-0.40,1.10) \\
0.65(-0.49,1.79)\end{array}$ \\
\hline $0-24$ months & $\begin{array}{l}\text { EDSS } \\
\text { AI }\end{array}$ & 19 & $\begin{array}{l}0.58 \\
1.21\end{array}$ & 17 & $\begin{array}{l}0.97 \\
2.06\end{array}$ & $\begin{array}{l}0.39(-0.45,1.23) \\
0.85(-0.53,2.22)\end{array}$ \\
\hline
\end{tabular}

respectively. When treatment "failure" is defined as a sustained one-step worsening on the EDSS, there were seven failures in each group, distributed similarly in time $(p=0.89$, logrank test).

Multiple regression was also used to examine mean EDSS change at one year within the CTX group, in relation to total $\mathrm{mg}$ of CTX received, total $\mathrm{mg}$ of CTX per $\mathrm{kg}$ of body weight, lowest leucocyte count during the treatment period, and lowest lymphocyte count. The overall R2 was $0.16(p=0.34)$. Disease progression during the year subsequent to treatment was only slightly related to these indicators of treatment intensity.

Dichotomous measures of first year changes in level of neurological impairment specific to several functional systems are presented in table 5. There is no evidence of more stability in the CTX group at one year for any of the functions. At two years, there was more stability in the CTX group, but all group differences could be a result of chance alone.

Dichotomous measures of change from the baseline to the two year follow up in each of the components of the IS and the ES are presented in table 6 . The IS, like the FSS, suggests that after two years the FA patients deteriorated more than the CTX patients. The proportions of CTX patients who were stable or worse were similar to those of FA patients.

\section{Discussion}

Our results provide little support for the hypothesis that a short course of intensive immunosuppression with CTX favourably modifies the course of chronic progressive MS. Change in level of neurological impairment from the baseline examination to one year follow up in the CTX group was similar to that in the control group. On average, the patients in both groups deteriorated substantially.

At the 18 and 24 month follow up examinations, the CTX group was somewhat more stable than the control group. If there is (as we have found) no benefit at one year, then the differences between the groups that appear during the second year may well be a result of chance alone. The rather marked contrasts between the groups on several of the IS items at two year follow up, associated with nominal $p$ values below 0.05 , are interesting and puzzling.

Table 5 Change in level of impairment from baseline to 12 month follow up by functional system and treatment group

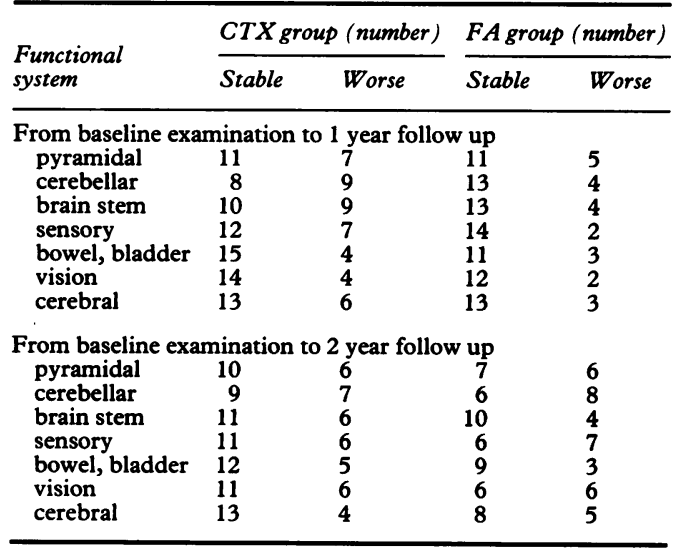


Table 6 Change in incapacity status and environmental status by treatment group

\begin{tabular}{|c|c|c|c|c|}
\hline \multirow[b]{2}{*}{ Category } & \multicolumn{2}{|c|}{$\begin{array}{l}\text { CTXgroup } \\
\text { (number) }\end{array}$} & \multicolumn{2}{|c|}{$\begin{array}{l}\text { FA group } \\
\text { (number) }\end{array}$} \\
\hline & Stable & Worse & Stable & Worse \\
\hline $\begin{array}{l}\text { Incapacity status } \\
\text { stair climbing } \\
\text { ambulation } \\
\text { transfers` } \\
\text { bowel } \\
\text { bladder } \\
\text { bathing } \\
\text { dressing }^{\star} \\
\text { grooming } \\
\text { feeding } \\
\text { vision } \\
\text { speech } \\
\text { physical problems } \\
\text { societal role } \\
\text { fatigability } \\
\text { psychic function }\end{array}$ & $\begin{array}{l}14 \\
11 \\
13 \\
16 \\
16 \\
12 \\
12 \\
15 \\
15 \\
15 \\
15 \\
16 \\
14 \\
17 \\
14\end{array}$ & $\begin{array}{l}5 \\
8 \\
6 \\
2 \\
3 \\
7 \\
7 \\
4 \\
4 \\
3 \\
4 \\
3 \\
5 \\
2 \\
5\end{array}$ & $\begin{array}{r}10 \\
9 \\
6 \\
14 \\
14 \\
4 \\
6 \\
9 \\
9 \\
11 \\
12 \\
14 \\
12 \\
16 \\
14\end{array}$ & $\begin{array}{r}10 \\
11 \\
14 \\
6 \\
6 \\
16 \\
14 \\
11 \\
11 \\
7 \\
8 \\
6 \\
8 \\
3 \\
5\end{array}$ \\
\hline $\begin{array}{l}\text { Environmental status } \\
\text { work } \\
\text { financial } \\
\text { residence } \\
\text { personal assistance } \\
\text { transportation } \\
\text { health services use }\end{array}$ & $\begin{array}{l}14 \\
14 \\
10 \\
14 \\
14 \\
17\end{array}$ & $\begin{array}{l}3 \\
5 \\
9 \\
5 \\
5 \\
2\end{array}$ & $\begin{array}{l}15 \\
14 \\
10 \\
12 \\
12 \\
15\end{array}$ & $\begin{array}{r}5 \\
5 \\
10 \\
8 \\
8 \\
5\end{array}$ \\
\hline
\end{tabular}

${ }^{\star} \mathrm{p}<0 \cdot 10$, using two-tailed, continuity-adjusted chi-squared test.

They should be interpreted cautiously because we tested a rather large number of interrelated comparisons. Also, our study design included a second year of follow up only to examine whether treatment benefits shown at one year could be sustained. We continued with the second year because we could not rule out substantial treatment benefits at one year until most patients had completed most or all of their second year of follow up.

On average the condition of the treatment group did not deteriorate much during the second year. Regardless of treatment, more deterioration might be expected during the first year than during the second year if: our eligibility criteria require that each patient's MS be acute and progressive at the outset of the first year; with no such requirement at the outset of the second year, we would not be surprised to find more patients temporarily stable. But we can think of no good reason to expect a delay of one year before differences between the groups attributable to the relative benefits of brief immune suppression begin to appear.

With only 20 or 22 patients in each group, data from several patients may have consider- able leverage upon our results. Our decisions about how to handle data from the motor neuron disease patient, the two "crossover" FA patients who received CTX, and the patients for whom we lack second year follow up are debatable.

We again made the comparisons shown in the figure and in tables 4-6, following three alternatives: 1) including the FA patient with motor neuron disease; 2) omitting the two "crossovers," after the time at which they received CTX; and 3) assigning the last observed EDSS to the two patients who died of other causes and the four patients whose two year follow up is not complete. Overall, our results change very little in these alternative analyses.

We recognise that neither EDSS change nor change in any of our other measures is a valid indicator of overall disease progression. We chose the EDSS for our primary indicator because it provides a measurement of functional disability and is a standard in MS research. To the extent that our outcome measures are imprecise, we have somewhat less than $95 \%$ confidence in the " $95 \%$ " confidence intervals we report.

It is worth noting that the three most improved patients and the three patients who died were all in the CTX group. One of the three deaths was caused by MS. Of the three improved patients, one (patient 1) first showed improvement at 12 month follow up; another (patient 6 ) at 18 months; and the third (patient 31 ) at 24 months. We cannot rule out immune suppression therapy as responsible for their improvement. With a total of 42 or 43 patients, we have little ability to examine the possibility of treatment benefits among limited subgroups of patients.

Studies of CTX treatment in MS are tallied by comparison group and outcome (table 7). Patient groups studied have been of disparate progression types and required widely varying treatment regimes. Some have used randomised treatment programmes with comparison groups. The most promising reports have been those of Hauser et $a^{10}$ and Goodkin et al. ${ }^{15}$

In this study, CTX was used alone, without ACTH as an adjunct. The literature has indicated ACTH is not useful when used as the sole immunosuppressant in chronic progres-

Table 7 Results of cyclophosphamide treatment studies

\begin{tabular}{|c|c|c|c|c|c|c|c|c|c|c|}
\hline \multirow[b]{2}{*}{ Author } & \multirow{2}{*}{$\begin{array}{l}\text { CTX group } \\
\text { (dose, duration) }\end{array}$} & \multirow{2}{*}{$\begin{array}{l}\text { Progression } \\
\text { type }\end{array}$} & \multirow{2}{*}{$\begin{array}{l}\text { Comparison } \\
\text { group }\end{array}$} & \multirow{2}{*}{$\begin{array}{l}\text { Follow } \\
\text { up } \\
\text { (year) }\end{array}$} & \multicolumn{3}{|c|}{$C T X$} & \multicolumn{3}{|c|}{ Comparison } \\
\hline & & & & & $\operatorname{Imp}$ & Same & Worse & $\operatorname{Imp}$ & Same & Worse \\
\hline $\begin{array}{l}\text { Aimard }^{8} \\
\text { Girard }^{9} \\
\text { Gonsette }^{13} \\
\text { Drachman }^{12} \\
\text { Hommes }^{14}\end{array}$ & $\begin{array}{l}2 \mathrm{~g}, \mathrm{IV}, 1 \mathrm{dose} \\
200 \mathrm{mg}, \mathrm{IV}, 4-6 \mathrm{wk} \\
1-2 \mathrm{~g}, \text { total in } 2-3 \mathrm{wk} \\
4-5 \mathrm{mg} / \mathrm{kg}, \mathrm{IV}, 10 \mathrm{~d} \\
400 \mathrm{mg}, \mathrm{PO}, 21-28 \mathrm{~d} \text { plus } \\
\text { prednisone }\end{array}$ & $\begin{array}{l}\text { mixed } \\
\text { relapsing } \\
\text { chronic }\end{array}$ & $\begin{array}{l}\mathbf{n} / \mathbf{a} \\
\mathbf{n} / \mathbf{a} \\
\mathbf{n} / \mathbf{a} \\
\mathbf{n} / \mathbf{a} \\
\mathbf{n} / \mathbf{a}\end{array}$ & $\begin{array}{l}2 \cdot 5 \\
2-6 \\
21 \text { days } \\
1-5\end{array}$ & $\begin{array}{r}1 \\
17 \\
66 \\
1 \\
13\end{array}$ & $\begin{array}{r}13 \\
4 \\
14\end{array}$ & $\begin{array}{r}0 \\
44 \\
1 \\
12\end{array}$ & & & \\
\hline Carter $^{\star 16}$ & $\begin{array}{l}500 \mathrm{mg} \text {, daily to } 2.5 \text { to } \\
11.0 \mathrm{~g} \text { plus ACTH }\end{array}$ & chronic & $\mathbf{n} / \mathbf{a}$ & $!$ & 24 & 57 & 19 & & & \\
\hline $\begin{array}{l}\text { Millac }^{11} \\
\text { Hauser }^{10}\end{array}$ & $\begin{array}{l}75-100 \mathrm{mg} / \mathrm{kg}, \mathrm{PO}, 1 \mathrm{yr} \\
400-500 \mathrm{mg}, \mathrm{IV}, 10-14 \mathrm{~d} \\
\text { plus ACTH }\end{array}$ & $\begin{array}{l}\text { unspecified } \\
\text { chronic }\end{array}$ & $\begin{array}{l}\text { untreated } \\
\text { ACTH } \\
\text { plasma exchange }\end{array}$ & 1 & $\begin{array}{l}3 \\
8\end{array}$ & $\begin{array}{l}2 \\
8\end{array}$ & $\begin{array}{l}3 \\
4\end{array}$ & $\begin{array}{l}0 \\
1 \\
4\end{array}$ & $\begin{array}{l}3 \\
3 \\
5\end{array}$ & $\begin{array}{r}5 \\
16 \\
9\end{array}$ \\
\hline Goodkin ${ }^{15}$ & $\begin{array}{l}500 \mathrm{mg}, \mathrm{IV}, 10-14 \mathrm{~d} \\
\text { plus ACTH; } \\
\text { or } 700 \mathrm{mg} / \mathrm{m}^{2}, \mathrm{IV} \text {, weekly } \\
\text { up to } 6 \mathrm{plus} \text { prednisone }\end{array}$ & chronic & $\begin{array}{l}\text { untreated, } \\
\text { nonrandomised }\end{array}$ & $\begin{array}{l}1 \\
1 \cdot 5\end{array}$ & $\begin{array}{r}16 \\
14 \\
9\end{array}$ & & $\begin{array}{l}11 \\
13 \\
18\end{array}$ & $\begin{array}{l}4 \\
4 \\
1\end{array}$ & 21 & $\begin{array}{l}20 \\
20\end{array}$ \\
\hline $\begin{array}{l}\text { Likosky } \\
\text { (current } \\
\text { study) }\end{array}$ & $400-500 \mathrm{mg}, \mathrm{IV}, 3-44 \mathrm{~d}$ & chronic & folic acidt & $\begin{array}{l}1 \\
1 \cdot 5\end{array}$ & $\begin{array}{l}1 \\
2 \\
3\end{array}$ & $\begin{array}{l}13 \\
11\end{array}$ & $\begin{array}{l}8 \\
7 \\
6\end{array}$ & $\begin{array}{r}1 \\
2 \\
10\end{array}$ & $\begin{array}{r}13 \\
10 \\
0\end{array}$ & $\begin{array}{l}6 \\
8 \\
9\end{array}$ \\
\hline
\end{tabular}

n/a = no comparison group.

Imp = improved.

tCTX group includes 14 patients treated with maintenance CTX as long as two years.

†Randomised. 
sive MS. Rinne et al ${ }^{25}$ treated 73 MS patients, of whom 37 were in a chronic progressive form, in a randomised, double-blinded study with ACTH or placebo. Their results did not indicate a benefit to ACTH usage. Without reason to believe that ACTH would benefit patients in either group, we decided that the clinical trial would be simpler to conduct and interpret without administering ACTH. We are unable to comment on a possible synergy between ACTH and CTX.

Immunosuppressive effect was measured by the degree of leucopenia and lymphocytopenia. The mean dose of CTX administered $(70 \mathrm{mg} /$ $\mathrm{kg}$ ) was less than that reported by Hauser et al ${ }^{10}$ (80-100 mg/kg administered over 10-14 days) or Goodkin et al. ${ }^{15}$ This may partly reflect the effect of ACTH, which may mobilise polymorphonuclear cells from the bone marrow into the circulation and mildly increase the leucocyte count. An ACTH-stimulated baseline elevated leucocyte count may possibly result in a longer course of CTX before the leucocyte count falls below a target cut-off point of $4000 / \mathrm{mm}^{3}$. In addition, we administered CTX on a schedule of five days weekly, which may reduce the total dose required. Our mean pretreatment leucocyte and lymphocyte counts were 7855/ $\mathrm{mm}^{3}$ and $1677 / \mathrm{mm}^{3}$, respectively. Our mean values for leucopenia and lymphocytopenia were $2045 / \mathrm{mm}^{3}$ and $414 / \mathrm{mm}^{3}$, somewhat higher than those of the Hauser et al ${ }^{10}$ group, which were $1800 / \mathrm{mm}^{3}$ and $213 / \mathrm{mm}^{3}$. However, the degree of immunosuppression as measured by the degree of leucopenia or lymphocytopenia did not correlate with outcome in our study.

At one and two year follow up, $70 \%$ and $53 \%$ of the $20 \mathrm{FA}$ patients were stable using our primary measure of neurological impairment (that is, an improved EDSS or $<1$ point change). The pace of progression in our study is consistent with the longitudinal data of Confavreux et al, ${ }^{1}$ which showed variable duration from the onset of moderate disability (ambulatory) to the onset of severe disability (non-ambulatory). This period is age dependent and varies from $6 \cdot 1$ years in the third decade to four years in the sixth decade. Kelly ${ }^{26}$ comments on tendencies for disease progression in progressive MS to slow or halt unpredictably. This may partly explain the apparent slowing of disease progression in our patients after entry to the study.

We were able to demonstrate the safe use of high-dose immunosuppression in an outpatient clinic setting. This may be related partly to the safety precautions provided for each patient under the study protocol. We have not yet evaluated long-term CTX complications, which may include malignancies and sequelae of changes in immune system function.

This randomised, single-blinded clinical trial does not indicate that a short series of high-dose CTX favourably alters the course of chronic progressive MS. Although CTX immunosuppression therapy can be safely administered to MS patients in an outpatient clinic setting and modest benefits cannot be ruled out, it is doubtful that there are substantial benefits during the year after treatment.
The research was supported in part by the Community Service Program of Kaiser Foundation Hospitals. The study protocol was approved by the Kaiser Permanente Medical Care Program, Northern California Region, Institutional Review Board. Bristol Myers Oncology Division (Bristol Myers Company)
Evansville, Indiana, provided cyclophosphamide as Cytoxan.

The following Northern California Region Permanente Medical Group neurologists referred patients who were included in the study: Scott Abramson, Allan Bernstein, Gregory C Culberson, Charles Kane, Carlos Cromeyer, John Bissell, Raj Bhandari, John Cassidy, David O'Dell, Frank Wilson. Carolyn A Griffin assisted with the study.

Presented at the annual meeting of the American Academy of Neurology, New York, April 5-11 1987, and published in abstract form in Neurology 1987;37:108; and as a preliminary report in Neurology 1988;38:14-9.

1 Confavreux C, Aimard G, Devic M. Course and prognosis of multiple sclerosis assessed by the computerised data processing of 349 patients. Brain 1980;103:281-300.

2 Adams CW. Pathology of multiple sclerosis: progression of the lesion. Br Med Bull 1977;33:15-20.

3 Arnason BGW. Immunology of multiple sclerosis. In: Franklin EC, ed. Clinical immunology update: reviews for physicians. New York: Elsevier, 1983:235-59.

4 Lisak RP. Overview of the rationale for immunomodulating therapies in multiple sclerosis. Neurology 1988;83(Suppl 2):5-8.

5 Myers LW, Ellison GW, eds. Rationale for immunomodulating therapies of multiple sclerosis. Neurology 1988;38(Suppl 2).

6 McFarlin DE, McFarland HF. Multiple sclerosis: second of two parts. N Engl J Med 1982;307:1246-51.

7 Van Den Noort S. Future directions: where do we go from here? Neurology 1988;38(Suppl 2):88.

8 Aimard G, Girard P-F, Raveau J. Sclérose en plaques et processus d'auto-immunisation: traitement par les antiprocessus d'auto-immunisation: traitem
mitotiques. Lyon Med 1966;215:345-52.

9 Girard PF, Aimard G, Pellet H. Mouvement thérapeutique: les immuno-depresseurs (1): thérapeutique immunoles immuno-depresseurs (1): therapeutique ims en neurologie. Presse Med 1967;75:967-8.

10 Hauser SL, Dawson DM, Lehrich JR, et al. Intensive immunosuppression in progressive multiple sclerosis. N Engl J Med 1983;308:173-80.

11 Millac P, Miller H. Cyclophosphamide in multiple sclerosis (Letter). Lancet 1969;1:783.

12 Drachman DA, Paterson PY, Schmidt RT, Spehlmann RF. Cyclophosphamide in exacerbations of multiple sclerosis: therapeutic trial and a strategy for pilot drug studies. J Neurol Neurosurg Psychiatry 1975;38:592-7.

13 Gonsette RE, Demonty L, Delmotte P. Intensive immunosuppresson with cyclophosphamide in multiple sclerosis. J Neurol 1977;214:173-81.

14 Hommes OR, Lamers KJB, Reekers P. Effect of intensive immunosuppression on the course of chronic progressive immunosuppression on the course of chronic
multiple.sclerosis. J Neurol 1980;223:177-90.

15 Goodkin DE, Plencner S, Palmer-Saxerud JP, Tectzen M, Hertsgaard $D$. Cyclophosphamide in chronic progressive multiple sclerosis: maintenance vs nonmaintenance therapy. Arch Neurol 1987;44:826-7.

16 Carter JL, Hafler DA, Dawson DM, Orav J, Weiner HL. Immunosuppression with high dose IV cyclophosphamide and ACTH in progressive multiple sclerosis: cumulative 6-year experience in 164 patients. Neurology 1988;38(Suppl 2):9-14.

17 Mickey MR, Ellison GW, Fahey JL, Moody DJ, Myers $\mathrm{LW}$. Correlation of clinical and immunologic states in multiple sclerosis. Arch Neurol 1987;44:371-5.

18 Myers LW, Fahey JL, Moody DJ, Mickey MR, Frane MV, Ellison GW. Cyclophosphamide "pulses" in chronic Ellison GW. Cyclophosphamide "pulses" in chronic progressive

19 Calabresi P, Parks RE Jr. Chemotherapy of neoplastic diseases. In: Gilman AG, Goodman LS, Rall TW, Murad F, eds. Goodman and Gilman's The pharmacological basis of therapeutics, 7th ed. New York: Macmillan, 1985: 1240-306.

20 Schilsky RL, Lewis BJ, Sherins RJ, Young RC. Gonadal dysfunction in patients receiving chemotherapy for cancer. Ann Intern Med 1980;93(Pt 1):109-14.

21 Puri HC, Campbell RA. Cyclophosphamide and malignancy. (Letter). Lancet 1977;1:1306.

22 Schumacher GA, Beebe G, Kibler RF, et al. Problems of experimental trials of therapy in multiple sclerosis: report by the panel on the evaluation of experimental trials of therapy in multiple sclerosis. Ann NY Acad Sci 1965; 122:522-68.

23 Kurtzke JF. Rating neurologic impairment in multiple sclerosis: an expanded disability status scale (EDSS). Sclerosis: an expanded disa
Neurology 1983;33:1444-52.

24 IFMSS Minimal Record of Disability Neurological Assessment: Kurtzke Expanded Disability Status Scale EDSS ment: Kurtzke Expanded Disability Status Scale EDSS
(WHO Impairment). Acta Neurol Scand (Suppl 101) (WHO Impairme

25 Rinne UK, Sonninen V, Tuovinen T. Corticotrophin treatment in multiple sclerosis. Acta Neurol Scand 1968; 44:207-18.

26 Kelly R. Clinical aspects of multiple sclerosis. In: Koetsier JC, ed. Handbook of clinical neurology, vol 3. New York: Elsevier, 1985:49-78. 